\title{
Growth rate of bluegill sunfish (Lepomis macrochirus) maintained in groups and in isolation
}

\author{
BRUCE DRAGER and DAVID CHISZAR \\ University of Colorado, Boulder, Colorado 80309
}

\begin{abstract}
Bluegill sunfish (Lepomis macrochirus Rafinesque) were maintained under three conditions: grouped in a 454-liter aquarium $(n=5)$, grouped in a 76-liter aquarium $(n=5)$, and isolated (each fish in a 76-liter aquarium, $n=5$ ). Body weight was recorded across 320 days, and growth of isolated fish was compared with growth of subordinate individuals in group situations. Each set of five fish was rotated through grouped and isolated conditions during the study. Hence, the effect of change in social environment on growth rate was observed. Isolated individuals grew at a more rapid rate than subordinate individuals in groups. This was true for between-subjects as well as within-subjects comparisons. Growth rate changes consequent to manipulation of social conditions occurred rapidly (usually within 10 days).
\end{abstract}

When fish are raised in groups, subordinate individuals grow more slowly than dominants (Allee, Greenberg, Rosenthal, \& Frank, 1948; Brown, 1946; Symons, 1970). Stunted growth rates in subordinates have been observed in salmon, trout, cod, and bass (Brown, 1957). To observe whether social conditions influence growth rates in bluegill sunfish (Lepomis macrochirus Rafinesque), we compared growth of subordinate fish with that of isolated individuals. Additionally, this experiment measured growth rates of fish successively exposed to isolated and grouped conditions in order to permit within- and between-subjects assessment of the effects of social conditions.

\section{METHOD}

\section{Subjects}

Bluegill sunfish $(n=52)$ were obtained by seining local ponds in the fall of 1980 . These fish were maintained in a 946-liter aquarium for 4 weeks. After this acclimation period, 15 fish were selected as subjects and divided into three groups $(n=5)$. Subjects chosen for the experiment ranged from 10 to $12 \mathrm{~cm}$ in fork length and from 10 to $30 \mathrm{~g}$ (all were approximately 4 years old). Subjects were maintained throughout the study in glass aquaria. Water temperature was maintained at $25^{\circ} \mathrm{C} \pm 1^{\circ} \mathrm{C}$, and water quality in each tank was controlled by undergravel and externally mounted filters. Subjects were fed Purina Trout Chow (pellet size $=3 \mathrm{~mm}$ ), and each group received a total daily ration that was five times the greatest amount consumable by the largest fish in the study. Daily ration was offered in two equal halves (during photophase, 0700-1830 h); food not eaten was removed at $1830 \mathrm{~h}$.

\section{Procedure}

The experiment was divided into three phases. In Phase 1, Condition A consisted of five fish maintained as a group in a single 76-liter aquarium, Condition B contained five fish maintained as a group in a single 454-liter aquarium, and Condition C contained five fish that were housed separately in individual 76-liter aquaria. Weight and length measurements were taken at approximately 10-day intervals for 104 days (each fish was measured 10 times in Phase 1). In addition to growth measurements, behavioral observations were made of grouped fish to identify the subordinates (Alverez, 1975; Chiszar, Ashe, Seixas, \& Henderson, 1976; Rayor \& Chiszar, 1978).

In Phase 2 of the study, fish in Condition A were transferred as a group to a 454-liter aquarium, fish in Condition B were separated into individual 76-liter aquaria, and fish in Condition C were transferred individually into separate 76-liter aquaria. Growth measures were taken (as described above) for 104 days (each fish was measured 11 times in Phase 2). Behavioral observations were made of fish in Condition A (the only grouped fish), and subordinate individuals were again identified.

In the final phase of this study, fish in Condition A were now separated in individual 76-liter aquaria, fish in Condition B were transferred to new aquaria and maintained as isolates, and fish in Condition $\mathrm{C}$ were grouped into a single 76-liter tank. Growth was again observed as described above for 114 days (each fish was measured 10 times in Phase 3), and behavioral observations were made on fish in Condition $\mathrm{C}$ to identify subordinates.

\section{RESULTS}

The mean body weight of fish in each condition for the entire period of the study ( 322 days) is presented in Figure 1. Length measurements revealed the same pattern of results as weight measurements, so only analyses of the latter will be presented here. Mixed ANOVAs treated conditions as a between-subjects factor and successive weighing days as a repeatedmeasures factor. Separate ANOVAs were executed for each phase of this study. All $F$ ratios reported below are for Condition by Days interactions from post hoc ANOVAs that contrasted pairs of conditions. During Phase 1, fish in Condition C (isolates) had significantly greater growth rates than subordinate fish in Conditions $A$ and $B[F s(9,63)=10.23$ and 6.05 , respectively; ps $<.01]$. Growth rates of fish in Conditions A and B did not differ $(F<1)$. In Phase 2, the isolated fish in Conditions $\mathrm{B}$ and $\mathrm{C}$ grew significantly more rapidly than subordinate fish in Condition $A[F s(10,70)=8.18$ and 


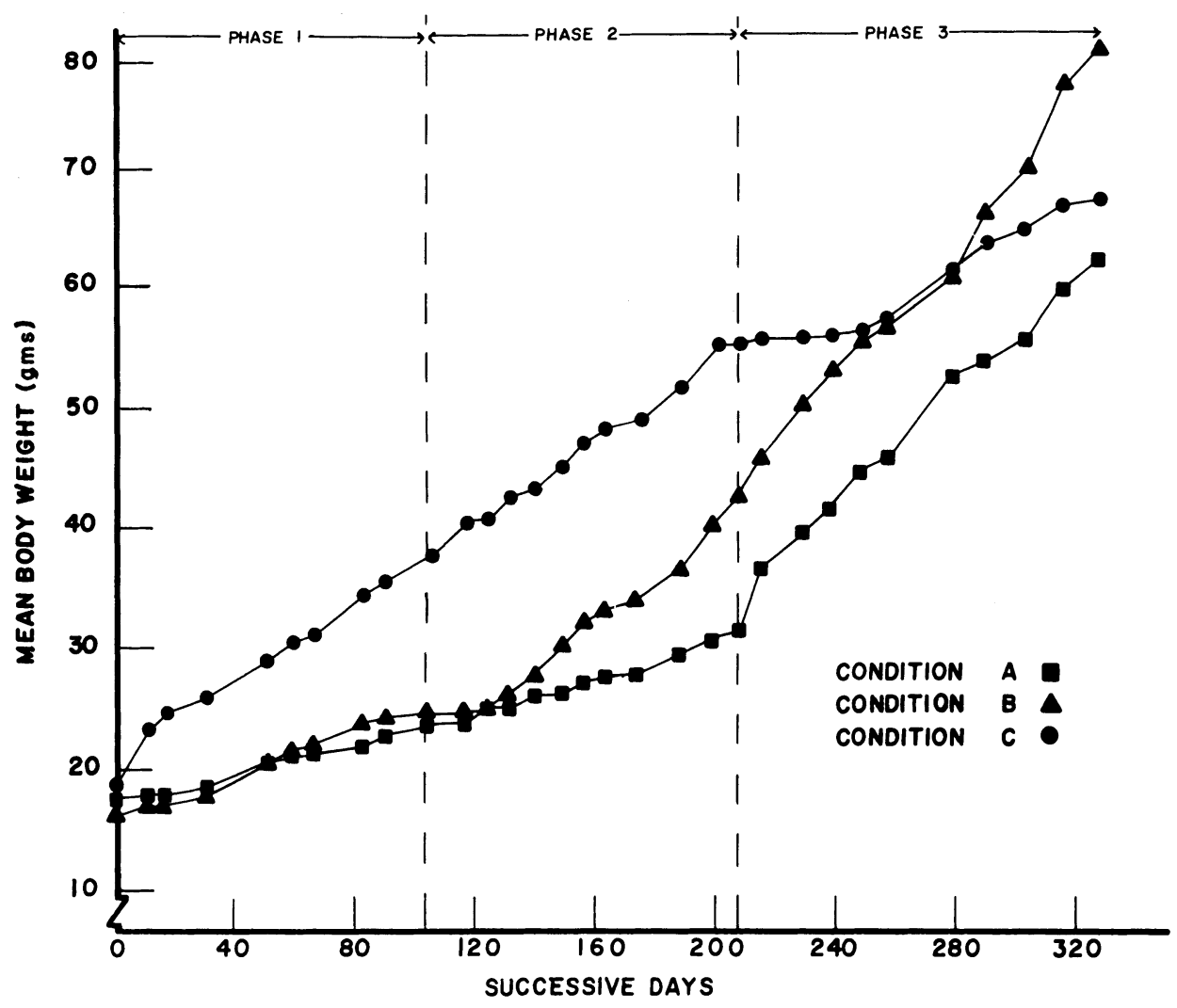

Figure 1. Growth rates for three sets $(n=5)$ of bluegill sunfish over 322 days. When fish were living in group situations (e.g., Phase 1, Conditions A and B), only data from subordinate animals were used in preparing this illustration and in the statistical analyses. In general, dominant fish grow at the same rate as isolated fish. Hence, including data from dominant animals in the means for grouped fish has the consequence of raising the mean and obscuring differences between grouped animals and isolated ones.

4.89 , respectively; ps $<.01]$. Growth rates of fish in Conditions $\mathrm{B}$ and $\mathrm{C}$ did not differ $(\mathrm{F}<1)$. Growth rate change from the stunted rate to the nonstunted rate occurred within 20 days in Condition B after fish were shifted from grouped maintenance to isolation.

In Phase 3 (beginning on Day 205), isolated fish in Conditions A and B had significantly greater growth rates than subordinate fish in Condition $\mathrm{C}[\mathrm{Fs}(9,54)=$ 5.09 and 13.09, respectively; ps $<.01]$. Growth rate reduction in Condition $\mathrm{C}$ (i.e., from nonstunted to stunted level) occurred almost immediately following the shift from isolated to grouped maintenance. There was, however, a reestablishment of the nonstunted growth rate after 40-50 days. Growth rate change from stunted to nonstunted level was displayed by fish in Condition A, and this occurred almost immediately after the shift from grouped to isolated maintenance.

Although growth rates for dominant fish have not been illustrated in Figure 1, these rates are statistically indistinguishable from rates shown by isolated fish. Hence, comparing growth rates of subordinates with growth rates of dominants reveals the same pattern of differences as comparison of subordinates with isolates.

\section{DISCUSSION}

Weight data from all three phases of this experiment indicate that growth rate of subordinate fish was significantly lower than that of isolated individuals. The observation in Phase 1 that grouped fish in a 76-liter aquarium grew at a rate comparable to that for fish raised in a 454-liter tank suggests that "space availability" was a relatively unimportant factor in determining growth in this study.

Data from Phases 2 and 3 indicate the reversibility of established growth rates of subordinates as well as isolates. Phase 2 demonstrated that fish that were grouped for over 3 months and that displayed relatively slow growth rates could rapidly adopt growth rates comparable to those of isolated individuals and maintain this rapid growth throughout the remainder of the study. Phase 3 indicated that the relatively rapid growth rates of isolated fish could be reversed by changing their social environment. However, the subsequent reestablishment of previous growth rate deserves additional study. The growth rate shifts in Phases 2 and 3 were consistent with earlier observations by Allee et al. (1948) on the green sunfish (Lepomis cyanellus). Hence, rate of growth in sunfish is facultative and rapidly modifiable by changes in social conditions.

It may be hypothesized that growth rate during the early years influences the subsequent ability of male bluegills to establish and defend territories. If this is true, then it may also be the case that early rapid growth rate predisposes males to adopt the territorial rather than the satellite (i.e., sneaker) reproductive 
strategy (cf. Keenleyside, 1972). The direction of causation will be difficult to establish since a genetic predisposition to become a satellite male may be associated with a predisposition toward subordinate status and, hence, toward stunted growth rate (cf. Dominey, 1980; Gross \& Charnov, 1980).

\section{REFERENCES}

Allee, W. C., Greenbera, B., Rosenthal, G. M., \& Frank, $P$. Some effects of social organization on growth in the green sunfish, Lepomis cyanellus. Journal of Experimental Zoology, 1948, 108, 1-20.

Alve rez, F. Social hierarchy under different criteria in groups of squirrel monkeys, Saimiri sciureus. Primates, 1975, 16, 437 455.

Brown, M. E. The growth of brown trout: Factors influencing the growth of brown trout fry. Journal of Experimental Biology, 1946, 22, 118-129.

Brown, M. E. The physiology of fishes (Vol. 1). New York: Academic Press, 1957.

Chiszar, D., Ashe, V., Seixas, S., \& Henderson, D. Social- aggressive behavior after various intervals of social isolation in bluegill sunfish (Lepomis macrochirus Rafinesque) in different states of reproductive readiness. Behavioral Biology, 1976, 16, 475-487.

Dominey, W. J. Female mimicry in male bluegill sunfish-A genetic polymorphism? Nature, 1980, 284, 546-548.

Gross, M. R., \& Charnov, E. L. Alternative male life histories in bluegill sunfish. Proceedings of the National Academy of Sciences, 1980, 7A, 6937-6940.

KeEnleyside, M. H. A. Intraspecific intrusions into nests of spawning longear sunfish (Pisces: Centrarchidae). Copeia, 1972, 272-278.

RAYOR, L. S., \& CHIszaR, D. Comparability of dominance indices in captive pigtail macacques (Macaca nemestrina). Bulletin of the Psychonomic Society, 1978, 12, 468-470.

Symons, P. E. K. The possible role of social and territorial behavior of Atlantic salmon parr in production of smolts. Technical Report: Fisheries Research Board of Canada, 1970, 206, 1-25.

(Received for publication September 9, 1982.) 